\title{
Theoretical study of electron-attracting ability of the nitro group: classical and reverse substituent effects
}

\author{
Olga A. Stasyuk ${ }^{1} \cdot$ Halina Szatylowicz ${ }^{1} \cdot$ Celia Fonseca Guerra $^{2} \cdot$ Tadeusz M. Krygowski $^{3}$
}

Received: 14 May 2015/Accepted: 30 May 2015/Published online: 17 June 2015

(c) The Author(s) 2015. This article is published with open access at Springerlink.com

\begin{abstract}
This study presents a quantum chemistry modeling of the substituent effect. For this purpose, a uniform approach-the model termed as "charge of substituent active region" (cSAR, defined as a sum of atomic charges at the substituent and the ipso carbon atom) - has been used. Its reliability has been confirmed by a quantitative description of the electron-attracting ability of the nitro group, and finally, the reverse substituent effect, showing the influence of reaction site $(\mathrm{Y})$ on the properties of substituent $(\mathrm{X})$, has been introduced and documented. The cSAR model has been applied to para-substituted nitrobenzene derivatives in which the nitro group acts either as a reaction site (classical substituent effect, with $\mathrm{X}=\mathrm{NO}_{2}, \mathrm{CN}, \mathrm{CHO}, \mathrm{COOMe}, \mathrm{COMe}, \mathrm{CF}_{3}, \mathrm{Cl}, \mathrm{H}, \mathrm{Me}$, $\mathrm{OMe}, \mathrm{NH}_{2}$ and $\mathrm{NHMe}$ ) or as a substituent (reverse substituent effect, with $\mathrm{Y}=\mathrm{NH}^{-}, \mathrm{NH}_{2}, \mathrm{H}$ and $\mathrm{NH}_{3}{ }^{+}$).
\end{abstract}

Dedicated to our friend Professor Alexandru T. Balaban of Texas A\&M University at Galveston in recognition of his outstanding contribution to theoretical and physical organic chemistry.

Electronic supplementary material The online version of this article (doi:10.1007/s11224-015-0608-6) contains supplementary material, which is available to authorized users.

Halina Szatylowicz

halina@ch.pw.edu.pl

Tadeusz M. Krygowski

tmkryg@chem.uw.edu.pl

1 Faculty of Chemistry, Warsaw University of Technology, Noakowskiego 3, 00-664 Warsaw, Poland

2 Department of Theoretical Chemistry and Amsterdam Center for Multiscale Modeling, VU University Amsterdam, De Boelelaan 1083, 1081 HV Amsterdam, The Netherlands

3 Department of Chemistry, Warsaw University, Pasteura 1, 02-093 Warsaw, Poland
Calculation was performed using BLYP functional with DFT-D3 correction and TZ2P basis set. Application of different assessments of atomic charges (Voronoi, Hirshfeld, Bader, Weinhold and Mulliken) leads to good correlation between calculated cSAR values.

Graphical Abstract Electron-attracting ability of the nitro group depends dramatically on the electron-donating properties of the reaction site

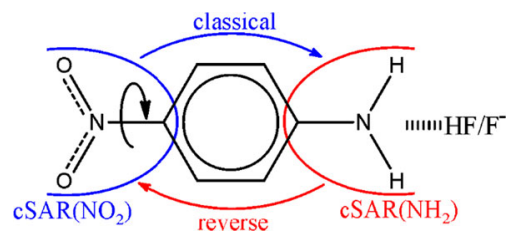

Keywords Substituent effects - Electron-attracting ability $\cdot$ Nitro group $\cdot$ Atomic charges

\section{Introduction}

Substituent effect is traditionally regarded in terms of Hammett constants [1], $\sigma$ (for reviews, see Refs. [2-7]). By definition, these constants rely on the ionization constants of para- and meta-substituted benzoic acids. The $\sigma$ constants have been used numerous times for the interpretation of chemical and physicochemical properties of $\mathrm{X}-\mathrm{R}-\mathrm{Y}$ systems $(\mathrm{X}$-substituent, $\mathrm{R}$ - transmitting moiety and $\mathrm{Y}$-reaction/process site) by using Hammett equation $[2,3,5,6]$ :

$\lg k_{\mathrm{p}, \mathrm{m}}=\lg k_{0}+\rho \sigma_{\mathrm{p}, \mathrm{m}}$

where $\sigma_{\mathrm{p}, \mathrm{m}}$ are substituent constants for para- and metapositions, and $k_{\mathrm{p}, \mathrm{m}}$ and $k_{0}$ are rate constants for substituted 
and unsubstituted systems, whereas $\rho$ is the reaction constant describing the sensitivity of the reaction/process on the substituent effect. In later works, $\lg k$ has often been replaced by $\mathrm{P}(\mathrm{X})$ - some quantitative characteristic of chemical or physicochemical properties. Soon, it became clear that the original Hammett constants fail in those cases where the electron-donating/attracting ability of the reaction site $\mathrm{Y}$ differs greatly from that of $\mathrm{COOH} / \mathrm{COO}^{-}$ groups in the Hammett's reference reaction. Therefore, for such reaction series in which moieties with strong electrondonating properties (EDP) are involved (e.g., ionization of phenols), new substituent constants have to be introduced, $\sigma_{\mathrm{p}}^{-}$(see Ref. [4]). The same applies to processes in which moieties with strong electron-attracting properties (EAP) participate (e.g., solvolysis of dimethylphenylcarbinyl chloride), yielding new constants [8], $\sigma_{\mathrm{p}}^{+}$. For example, in the case of the nitro group, the original $\sigma_{\mathrm{p}}=0.78$, whereas $\sigma_{\mathrm{p}}^{-}=1.27$ [7], which implies almost doubling EAP of this group in the latter case.

Existence of many various scales of substituent constants [9-13] indicates the dependence of substituent properties on the feature of the reaction center. Therefore, two types of the substituent effects should be taken into account: classical and reverse ones. A general view of substituent effects is presented in Scheme 1. The classical substituent effect describes how $\mathrm{X}$ affects properties of $\mathrm{Y}$, whereas the influence of $Y$ (usually a reaction site) on the properties of the substituent $\mathrm{X}$ is defined as the reverse substituent effect.

The nitro group $[14,15]$ is one of the most important substituents in organic chemistry. The variability of its EAP is nicely illustrated by experimental measurements of the polarographic half-wave potentials, $E_{1 / 2}$, of the reversible one-electron reduction of substituted nitrobenzene derivatives carried out in aprotic solvents to avoid subsequent kinetics [16], as well as by their formal reduction potentials [17], $E^{0}$. In this way, the obtained $E_{1 / 2}$ as well as $E^{0}$ values are thermodynamic properties and may serve as reliable descriptors of relations between structure and energetic characteristics of the molecules. A convenient case is reduction of the nitrocompounds where less negative value of the half-wave potential denotes a stronger electron-attracting ability of the nitro group in a given compound. In particular, measured $E_{1 / 2}$ values are between $-0.800 \mathrm{~V}$ (for $p$-CN-nitrobenzene) and

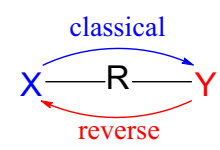

Scheme 1 Two kinds of substituent effects, $\mathrm{X}$ denotes substituent, $\mathrm{R}$ denotes transmitting moiety and $\mathrm{Y}$ denotes reaction/process site
$-1.400 \mathrm{~V}$ (for $p$-nitroaniline), and even $-1.700 \mathrm{~V}$ for 2-nitropropane [16].

As aforementioned, it is reasonable to introduce a concept of the reverse substituent effect. However, until now, no general and physically well-grounded way was found to describe it numerically. Certain solutions for this problem may come from the concept of the charge of substituent active region (cSAR) proposed by Sadlej-Sosnowska [1820]. cSAR was originally termed as qSAR but to avoid a confusion with commonly used Quantitative Structure Activity Relationships (QSAR) [21], a new abbreviation was introduced $[22,23]$. The value of $\operatorname{cSAR}(X)$ is a sum of the atomic charge $\mathrm{X}, q(\mathrm{X})$ and $q\left(\mathrm{C}_{\mathrm{ipso}}\right)$. Therefore, it is a quantitative measure of the electronic state of $\mathrm{X}$ and may depend on the moiety to which $\mathrm{X}$ is attached. The more negative $\operatorname{cSAR}(\mathrm{X})$ value is, the more electron-attractive is the group $\mathrm{X}$. It was found that there is a linear correlation between the cSAR values and the $\sigma_{\mathrm{p}}$ Hammett constants for a set of 21 para-substituted benzoic acids [18]. The slope of the obtained linear equation is negative with correlation coefficient, $c c$, and equal to -0.932 . It should be noted that for the same reaction series, there is no correlation between the charge at the substituent only, $q(\mathrm{X})$, and $\sigma_{\mathrm{p}}$ values $(c c=-0.126)$. Also in other cases, good correlations have been found for cSAR, both with $\sigma_{\mathrm{p}}$ for monosubstituted derivatives of benzene [19] and with SESE (substituent effect stabilization energy) for para-substituted nitrobenzene derivatives [23], as well as between $\operatorname{cSAR}(\mathrm{X})$ and $\operatorname{cSAR}(\mathrm{Y})$ for series of $\mathrm{X}-\mathrm{C}_{6} \mathrm{H}_{4}-\mathrm{Y}$ molecules [22].

The purpose of this paper is to show the effectiveness of the application of the cSAR concept for the description of the electron-attracting/donating properties of not only classical substituents but also to characterization of electronic propensity of any functional group. It will be demonstrated that cSAR concept can be used as a quantitative measure of both classical and reverse substituent effects in systems with two active groups located in paraposition with respect to each other. To show the classical substituent effect on the reaction site $\mathrm{Y}$, the one-electron reduction of the $\mathrm{NO}_{2}$ group in $p$-nitrobenzene-X derivatives (with $\mathrm{X}=\mathrm{NO}_{2}, \mathrm{CN}, \mathrm{CHO}, \mathrm{COOMe}, \mathrm{COMe}, \mathrm{CF}_{3}, \mathrm{Cl}$, $\mathrm{H}, \mathrm{Me}, \mathrm{OMe}, \mathrm{NH}_{2}$ and $\mathrm{NHMe}$ ) have been chosen as a model reaction. In this case, the $\mathrm{NO}_{2}$ group plays a role of the reaction site. However, much more important and definitely novel is application of cSAR model for description of the reverse substituent effect. For this purpose, the cSAR concept has been applied to $p$-nitrobenzene- $\mathrm{Y}$ derivatives (with $\mathrm{Y}=\mathrm{NH}^{-}, \mathrm{NH}_{2}, \mathrm{H}$ and $\mathrm{NH}_{3}{ }^{+}$), where EDP of the $\mathrm{Y}$ has been additionally modified by intermolecular $\mathrm{H}$-bonding. In this case, the $\mathrm{NO}_{2}$ group plays the role of the substituent $X$ and its properties will be investigated depending on the different electronic ability of the reaction site $\mathrm{Y}$. 


\section{Methodology}

Calculations were carried out with the Amsterdam Density Functional (ADF) program [24] using BLYP functional $[25,26]$ with DFT-D3 correction [27] including BeckeJohnson (BJ) damping [28] and TZ2P basis set [29]. The computed energy minima were verified to be equilibrium structures through vibrational analysis.

For assessment of the atomic charges, five different methods were used: Voronoi [30, 31], Hirshfeld [32], Mulliken [33-36], Bader [37] and Weinhold [38]. The first three of them were calculated using ADF program, whereas the last two types of charges were obtained using Gaussian 09 program [39] at BLYP/6-311++G(d,p) level of theory. Bader's AIM atomic charges were computed using AIMAll program [40]. Weinhold's natural population analysis (NPA) was performed with NBO 5.G program [41].

The charge of the substituent active region (cSAR) was calculated by summing up the atomic charges of all atoms of the group $\mathrm{X}$ and the charge at the ipso carbon atom to which the $\mathrm{X}$ is attached:

$\operatorname{cSAR}(\mathrm{X})=q(\mathrm{X})+q\left(\mathrm{C}_{\mathrm{ipso}}\right)$

To study the effect of intermolecular interactions on EAP of the nitro group, two types of H-bonded complexes of $p$-nitroaniline were simulated: (1) with neutral and (2) charge-assisted hydrogen bond. In the first case, $\mathrm{H}_{2} \mathrm{~N} \cdots \mathrm{HF}$ and $\mathrm{HNH} \cdots \mathrm{FH}$ interactions were considered. In the second one, $\mathrm{HNH} \cdots \mathrm{F}^{-}$and $\mathrm{HN}^{-} \ldots \mathrm{HF}$ interactions were taken into account. Different strengths of H-bond were achieved by elongation of the distance between $\mathrm{N}$ and $\mathrm{F}$ atoms from equilibrium to $4.0 \AA$

\section{Results and discussion}

This section is organized in three parts. In the first one, the assumption that the cSAR values computed by using various assessments of the atomic charges lead to qualitatively equivalent results will be verified. The next part will be devoted to a verification of the hypothesis that such intramolecular characteristic of the electron-attracting ability of the nitro group as the $\operatorname{cSAR}\left(\mathrm{NO}_{2}\right)$ can be an appropriate description of the external electron transfer properties measured for para-substituted nitrobenzene derivatives by the formal potentials or the polarographic half-wave potentials of reversible one-electron reduction. The third part will be focused on application of the cSAR concept to X-R-Y systems, where two kinds of the substituent effect may be observed: (1) the classical one, related to cases where substituent $X$ influences properties of the reaction/process site $\mathrm{Y}$, and (2) the reverse effect, which is manifested in changes of EAP of $\mathrm{NO}_{2}$ group depending on the kind of reaction/process site Y.

\section{Do cSAR values depend on the charge analysis method?}

It is well known that the Voronoi [30, 31], Hirshfeld [32], Mulliken [33-36], Bader [37] and Weinhold [38] methods for calculation of atomic charges give often qualitatively similar insights but quantitatively values differ [31, 42, 43]. Therefore, to avoid unreliable treatment in using of cSAR approach, we have computed $\operatorname{cSAR}(\mathrm{X})$ and cSAR $\left(\mathrm{NO}_{2}\right)$ values for $p$-nitrobenzene-X derivatives $\left(\mathrm{X}=\mathrm{NO}_{2}, \mathrm{CN}, \mathrm{CHO}, \mathrm{COOMe}, \mathrm{COMe}, \mathrm{CF}_{3}, \mathrm{Cl}, \mathrm{H}, \mathrm{Me}\right.$, $\mathrm{OMe}, \mathrm{NH}_{2}$ and $\mathrm{NHMe}$ ) using all aforementioned assessments of the atomic charges. The $\operatorname{cSAR}(\mathrm{X})^{\mathrm{VDD}}$ values (the Voronoi Deformation Density method is used for computing atomic charges) plotted against the data obtained from Hirshfeld, Mulliken, Bader and Weinhold approaches are well correlated (Fig. 1, data in Tables $\mathrm{S} 1, \mathrm{~S} 2)$. Thus, it can be concluded that qualitatively all these approaches are nearly equivalent for estimation of $\operatorname{cSAR}(\mathrm{X})$ values. Furthermore, the slopes for these linear regressions are close to 1 and amount to $0.86,1.22,1.01$ and 1.24 , respectively. However, these regressions are not sufficiently precise to recalculate $\operatorname{cSAR}(\mathrm{X})$ values from one method to the values of another one. Nevertheless, it confirms that within a given method, the final results are quite reliable.

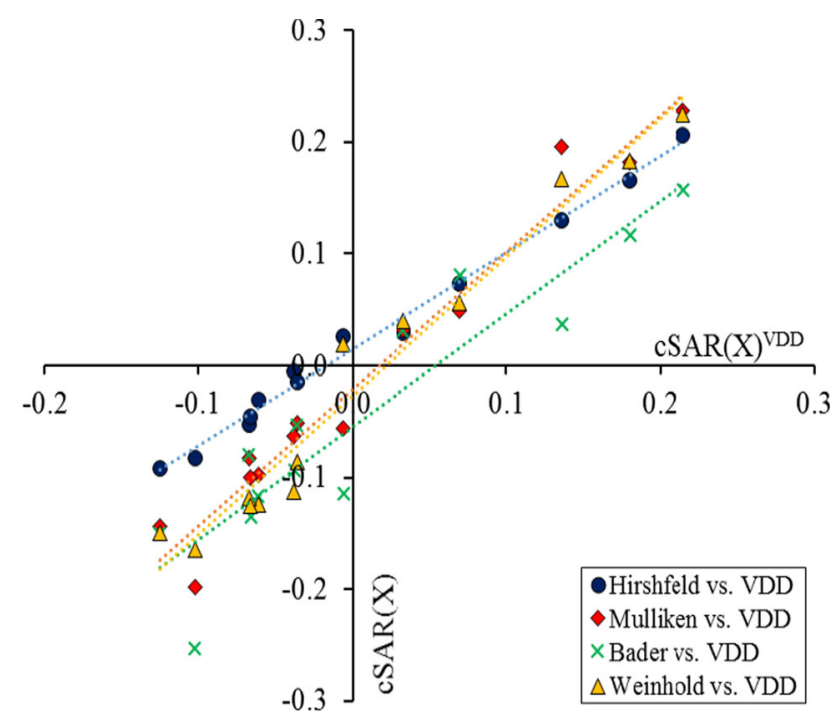

Fig. 1 Linear regressions between $\operatorname{cSAR}(\mathrm{X})$ values calculated by VDD method and data from Hirshfeld, Mulliken, Bader and Weinhold approaches for $p$-nitrobenzene- $\mathrm{X}$ derivatives with $\mathrm{X}=\mathrm{NO}_{2}, \mathrm{CN}$, $\mathrm{CHO}, \mathrm{COOMe}, \mathrm{COMe}, \mathrm{CF}_{3}, \mathrm{Cl}, \mathrm{H}, \mathrm{Me}, \mathrm{OMe}, \mathrm{NH}_{2}$ and $\mathrm{NHMe}$ $(c c=0.996,0.981,0.923$ and 0.982 , respectively) 
A rather good agreement between $\operatorname{cSAR}(\mathrm{X})$ values estimated by different approaches results from the fact that the substituent active region includes $\mathrm{C}_{\mathrm{ipso}}$, and the region boundary of $\mathrm{cSAR}(\mathrm{X})$ goes through two $\mathrm{CC}$ bonds which are less polarized. This is not the case when the charges of only the substituent are taken into account. The $\mathrm{C}-\mathrm{X}$ bond is usually much more strongly polarized, and the partitioning of space between the $\mathrm{C}$ and $\mathrm{X}$ atom can have there a large effect on $q(\mathrm{X})$ [31].

Figure 2 presents the analogous results for the cSAR $\left(\mathrm{NO}_{2}\right)$ values treated in the same way (data in Table S3). Correlations are even better due to a uniformity of the substituent active region (only for $\mathrm{NO}_{2}$ group). Importantly, the values of $\mathrm{cSAR}\left(\mathrm{NO}_{2}\right)$ and $\mathrm{cSAR}(\mathrm{X})$ are strongly correlated (Figure S1) which agrees with results obtained by Siodla et al. [22].

According to the work by Fonseca Guerra et al. [31], the VDD method is basis set independent and yields chemically meaningful atomic charges. Therefore, all further cSAR data will be calculated using this approach $[30,31]$, and the superscript VDD will be omitted.

\section{$\operatorname{cSAR}\left(\mathrm{NO}_{2}\right)$ as a numerical characteristic of the EAP of the $\mathrm{NO}_{2}$ group}

As mentioned in the Introduction, the experimental potentials of the reversible one-electron reduction of the nitro group in different nitrocompounds are in a wide range of measured values. These data may be used for answering the question: Does the electron acceptance of the nitro group (i.e., electroreduction) in various chemical species

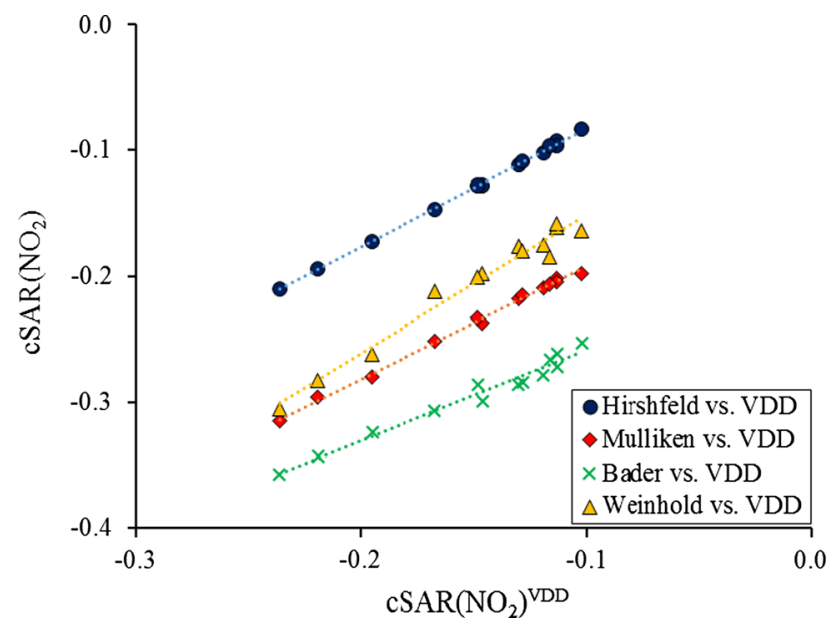

Fig. 2 Correlation between cSAR $\left(\mathrm{NO}_{2}\right)$ calculated from VDD charges and data from Hirshfeld, Mulliken, Bader and Weinhold methods for $p$-nitrobenzene-X derivatives with $\mathrm{X}=\mathrm{NO}_{2}, \mathrm{CN}, \mathrm{CHO}$, COOMe, $\mathrm{COMe}, \mathrm{CF}_{3}, \mathrm{Cl}, \mathrm{H}, \mathrm{Me}, \mathrm{OMe}, \mathrm{NH}_{2}$ and $\mathrm{NHMe}(c c=0.999$, $0.998,0.986$ and 0.986 , respectively) follow the trend in EAP values estimated by using of the cSAR concept?

Table 1 presents the half-wave potentials $\left(E_{1 / 2}\right)$ for $p$-nitrobenzene-X derivatives measured in dimethylformamide with tetrammonium perchlorate as a supporting electrolyte [16] as well as the formal reduction potentials $\left(E^{0}\right)$ measured in dry acetonitrile with tetra- $n$-butylammonium hexafluorophosphate as supporting electrolyte [17], substituent $\mathrm{X}$ constants $\left(\sigma_{\mathrm{p}}, \sigma_{\mathrm{p}}^{+}\right)$and cSAR values. Since both sets of experimental data are highly correlated to each other with $c c=0.998$ (see Figure S2), we will apply only $E^{0}$ values in the rest of this study. Additionally, good linear dependencies of the formal reduction potentials on Hammett's $\sigma_{\mathrm{p}}(\mathrm{X})$ and $\sigma_{\mathrm{p}}^{+}(\mathrm{X})$ have been also found with $c c=-0.956$ and -0.940 , respectively (Figure S3).

The most interesting is relationship between experimental $\left(E^{0}\right)$ and theoretical (cSAR) characteristics of the nitro group presented in Fig. 3. As can be seen, there is a qualitative equivalence between these two properties $(c c=-0.957)$. This means that the cSAR concept can be used for numerical characteristic of electronic properties of the nitro group. Deeper analysis of the scatter plot presented in Fig. 3 reveals that total dependence can be formed by two groups of substituted systems: the first one-by the systems with electron-donating substituents and the other one (steeper)—by the systems with electronaccepting groups. The same effect is also observed for other methods of charge assessment (see Figure S4). This can be explained from the fact that $E^{0}$ values represent a whole molecule property related to LUMO energy $\left(c c=0.997\right.$ for $E^{0}$ vs. LUMO, see Figure S5), whereas $\mathrm{cSAR}\left(\mathrm{NO}_{2}\right)$ is a local description of the electronic state of the nitro group.

As mentioned earlier, substituent effect means a description of the influence of $\mathrm{X}$ on the properties of $\mathrm{Y}$ in the $\mathrm{X}-\mathrm{R}-\mathrm{Y}$ systems. This may be named as a classical substituent effect that is usually treated by original Hammett approach. If the reaction site $\mathrm{Y}$ affects, in turn, the properties of the substituent $\mathrm{X}$, we deal with a reverse substituent effect. It should be stressed that in the former case charge distribution is based only on the intramolecular interactions, whereas in the latter one intermolecular interactions also influence electronic properties of the reaction site. para-Substituted nitrobenzene can be considered as a vivid example of both effects.

To show the classical substituent effect on the reaction site $\mathrm{Y}$, the one-electron reduction of the $\mathrm{NO}_{2}$ group in $p$ nitrobenzene- $\mathrm{X}$ derivatives (Table 1 ) have been chosen as a model reaction. In this case, the $\mathrm{NO}_{2}$ group plays a role of the reaction site $\left(\mathrm{Y}=\mathrm{NO}_{2}\right)$.

Manifestation of the classical substituent effect can be observed when we change the EAP/EDP of the substituent $\mathrm{X}$ and look at the response of the reaction site $\mathrm{Y}$. As a 
Table 1 Experimental data of negative values of polarographic half-wave potentials $^{\mathrm{a}}\left(E_{1 / 2}\right)$, formal reduction potentials $\mathrm{s}^{\mathrm{b}}\left(E^{0}\right)$ for $p$-nitrobenzene-X derivatives, as well as characteristics of the substituents: $\sigma_{\mathrm{p}}^{\mathrm{c}}, \sigma_{\mathrm{p}}^{+\mathrm{c}}, \mathrm{cSAR}$ values

\begin{tabular}{lllcccr}
\hline $\mathrm{X}$ & $-E_{1 / 2} / \mathrm{V}$ & $-E^{\circ} / \mathrm{V}$ & $\sigma_{\mathrm{p}}(\mathrm{X})$ & $\sigma_{\mathrm{p}}^{+}(\mathrm{X})$ & $\mathrm{cSAR}\left(\mathrm{NO}_{2}\right)$ & $\mathrm{cSAR}(\mathrm{X})$ \\
\hline $\mathrm{NO}_{2}$ & 0.580 & 1.056 & 0.78 & 0.79 & -0.102 & -0.102 \\
$\mathrm{CN}$ & 0.800 & 1.228 & 0.66 & 0.66 & -0.113 & -0.125 \\
$\mathrm{CHO}$ & 0.800 & 1.236 & 0.42 & 0.73 & -0.113 & -0.067 \\
$\mathrm{COOH}$ & - & - & 0.45 & 0.42 & -0.119 & -0.061 \\
$\mathrm{COOMe}$ & 0.885 & - & 0.45 & 0.49 & -0.130 & -0.038 \\
$\mathrm{COMe}$ & - & 1.292 & 0.50 & - & -0.128 & -0.036 \\
$\mathrm{CF}_{3}$ & - & 1.302 & 0.54 & 0.61 & -0.116 & -0.066 \\
$\mathrm{Cl}$ & 1.020 & 1.412 & 0.23 & 0.11 & -0.148 & -0.006 \\
$\mathrm{H}$ & 1.100 & 1.492 & 0.00 & 0.00 & -0.146 & 0.033 \\
$\mathrm{Me}$ & - & 1.547 & -0.17 & -0.31 & -0.167 & 0.070 \\
$\mathrm{OMe}$ & - & 1.615 & -0.27 & -0.78 & -0.195 & 0.136 \\
$\mathrm{NH}_{2}$ & 1.400 & 1.691 & -0.66 & -1.31 & -0.219 & 0.180 \\
$\mathrm{NHMe}$ & - & 1.739 & -0.70 & -1.81 & -0.236 & 0.215
\end{tabular}

${ }^{a}$ Data taken from Ref. [16]

b Data taken from Ref. [17]

c Substituent constants taken from Ref. [7] measure of electronic properties of the substituents Hammett's constants, $\sigma_{\mathrm{p}}(\mathrm{X})$ and $\sigma_{\mathrm{p}}^{+}(\mathrm{X})$, as well as cSAR $(\mathrm{X})$ values can be used, whereas a reply of the nitro group on electronic changes can be evaluated by two characteristics-reduction potentials and $\operatorname{cSAR}\left(\mathrm{NO}_{2}\right)$ values.

The most important dependence supporting the classical substituent effect is a linear correlation between calculated cSAR(X) and experimental $E^{0}$ as well as obtained cSAR $\left(\mathrm{NO}_{2}\right)$ values (Figs. 4, 5, S6). Therefore, it can be

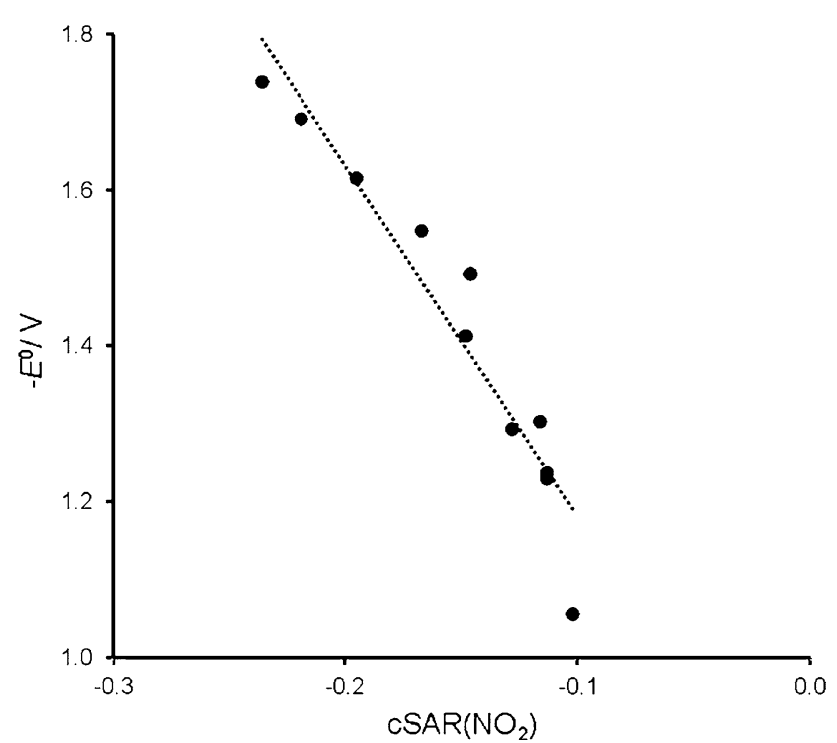

Fig. 3 Relationship between formal reduction potentials [17] $\left(E^{0}\right)$ and CSAR values of the nitro group for $p$-nitrobenzene- $\mathrm{X}$ derivatives with $\mathrm{X}=\mathrm{NO}_{2}, \mathrm{CN}, \mathrm{CHO}, \mathrm{COOMe}, \mathrm{COMe}, \mathrm{CF}_{3}, \mathrm{Cl}, \mathrm{H}, \mathrm{Me}, \mathrm{OMe}$, $\mathrm{NH}_{2}$ and $\mathrm{NHMe}(c c=-0.957)$ concluded that for $p$-nitrobenzene- $\mathrm{X}$ derivatives any modification in the electronic properties of substituent $\mathrm{X}$ implies the changes in the cSAR values of the reaction site, i.e., $\mathrm{X}$ influences the properties of the nitro group in a direct way.

Additionally, in support of the idea presented by SadlejSosnowska [18], good linear correlations between $\operatorname{cSAR}(\mathrm{X})$ values and Hammett's constants, $\sigma_{\mathrm{p}}$ and $\sigma_{\mathrm{p}}^{+}$, have been found with $c c=-0.985$ and -0.979 , respectively (see Figure S7).

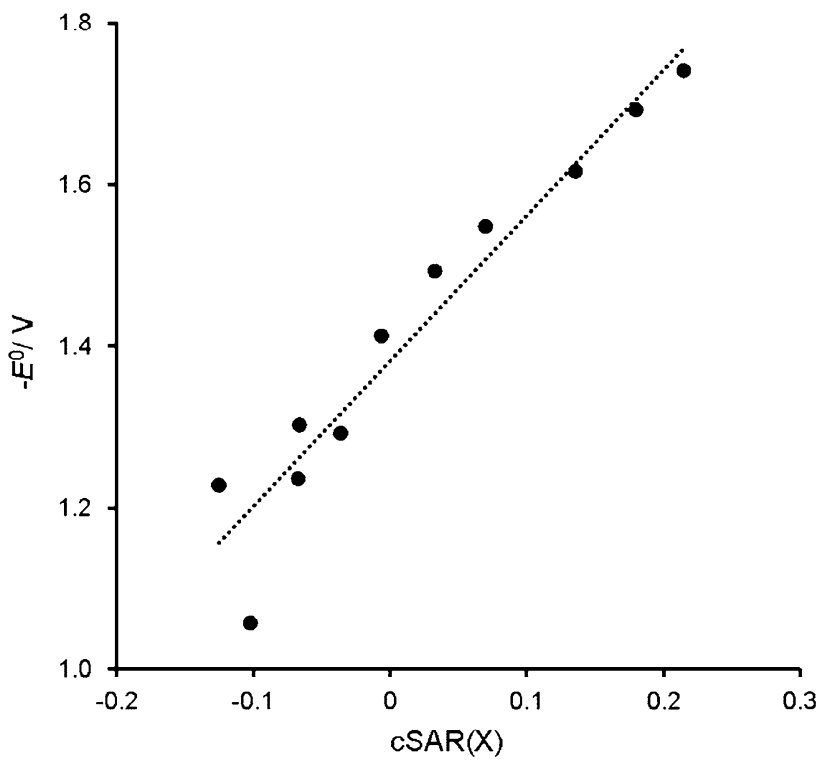

Fig. 4 Relationship between formal reduction potentials [17] and $\operatorname{cSAR}(X)$ values for $p$-nitrobenzene-X derivatives with $\mathrm{X}=\mathrm{NO}_{2}$, $\mathrm{CN}, \mathrm{CHO}, \mathrm{COOMe}, \mathrm{COMe}, \mathrm{CF}_{3}, \mathrm{Cl}, \mathrm{H}, \mathrm{Me}, \mathrm{OMe}, \mathrm{NH}_{2}$ and $\mathrm{NHMe}$ ( $c c=0.962)$ 


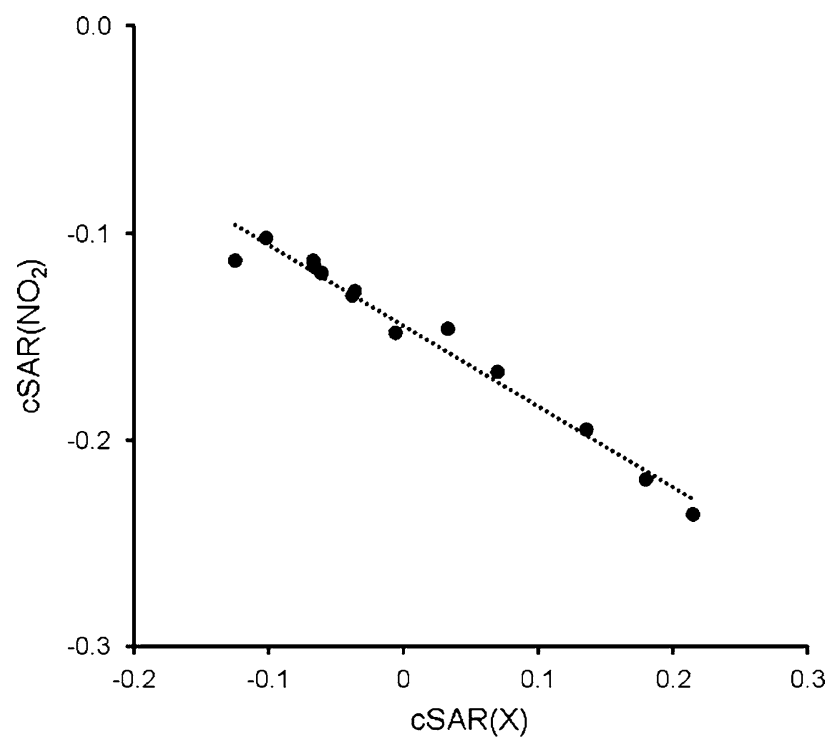

Fig. 5 Linear correlation between $\operatorname{cSAR}(\mathrm{X})$ and $\mathrm{cSAR}\left(\mathrm{NO}_{2}\right)$ values for $p$-nitrobenzene- $\mathrm{X}$ derivatives $(c c=-0.986)$

As was already shown by $\sigma_{\mathrm{p}}$ and $\sigma_{\mathrm{p}}^{-}$values, the EAP of the nitro group depends on the reaction site and changes almost twice. Therefore, to illustrate how the EAP of substituent $X$ can vary depending on the presence of another active group Y (reverse substituent effect), we have applied the cSAR concept to the $p$-nitrobenzene-Y derivatives. In this case, we change the electronic properties of the reaction site $\mathrm{Y}$ and observe changes in EAP of the nitro group, which here acts as substituent. For this purpose, following $\mathrm{Y}$ have been chosen: $\mathrm{H}, \mathrm{NH}_{3}{ }^{+}, \mathrm{NH}_{2}$ and $\mathrm{NH}^{-}$. Additionally, EDP of the last two $\mathrm{Y}$ has been modified by introducing the intermolecular H-bonding with $\mathrm{HF} / \mathrm{F}^{-}$( see Scheme 2). In order to investigate the effect of $\mathrm{H}$-bond strength on the electronic properties of the $\mathrm{NO}_{2}$ group, both equilibrium $\left(d_{\mathrm{N} \cdots \mathrm{F}}=\mathrm{opt}\right)$ and simulated $\left(d_{\mathrm{N} \cdots \mathrm{F}}=4.0 \AA\right)$ complexes have been regarded.

As a starting point of the discussion on reverse substituent effect, cSAR $\left(\mathrm{NO}_{2}\right)=-0.146$ for nitrobenzene

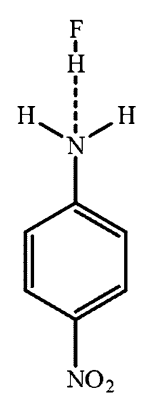

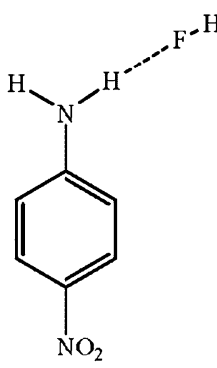

b

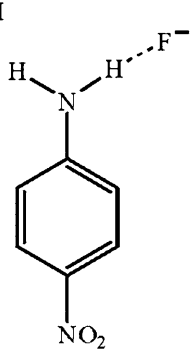

c

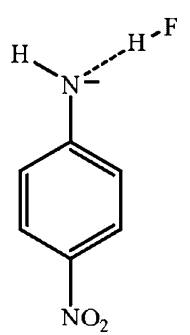

d
Scheme 2 Schematic representation of the studied H-bonded complexes should be chosen (row 2 in Table 2), where the electron flow takes place only between benzene ring and the nitro group and the possibility of an external electron flow is absent. This value of cSAR indicates the moderate EAP of the nitro group, which can be modified by introducing an electron-donating/attracting group in the para-position.

As expected, EAP of the $\mathrm{NO}_{2}$ group in the $p$-nitroanilinium cation (row 1 in Table 2) is the weakest among all studied cases with $\mathrm{cSAR}\left(\mathrm{NO}_{2}\right)=-0.019$. The reason of such lowering of this group attracting properties lies on a strong electron-withdrawing inductive effect of the positively charged $\mathrm{NH}_{3}{ }^{+}$which promotes small positive charges on the ortho- and para-positions, and prevents the resonance effect between ring and the nitro group. In turn, $\mathrm{NH}_{2}$ in $p$ nitroaniline (pNA, 5) causes a decrease of the $\operatorname{cSAR}\left(\mathrm{NO}_{2}\right)$ value down to -0.219 , via extra electrons donating through the ring. Such donating effect of the nitrogen lone pair in $\mathrm{NH}_{2}$ can be disturbed by intermolecular interactions involving $\mathrm{H}$-bonding (a, b and $\mathbf{c}$ in Scheme 2). $\mathrm{N} \cdots \mathrm{H}$ interactions result in a monotonic increase of $\mathrm{cSAR}\left(\mathrm{NO}_{2}\right)$ with strengthening of the H-bond (rows 3 and 4 in Table 2). In these cases, an electron outflow from pNA is observed which supplies electrons to the region of the intermolecular interactions. However, $\mathbf{b}$ and $\mathbf{c}$ types of complexes with $\mathrm{H} \cdots \mathrm{F}$ interactions shown in Scheme 2 demonstrate an opposite effect on EAP of the nitro group. This is confirmed by the $\mathrm{cSAR}\left(\mathrm{NO}_{2}\right)$ value decreasing down to -0.399 (rows 6-9 in Table 2). This can be explained by an electron transfer from $\mathrm{HF} / \mathrm{F}^{-}$to $\mathrm{pNA}$ which helps the nitro group to reveal stronger electron-attracting properties.

In the last type of complexes (d in Scheme 2), the negative charge at the nitrogen atom promotes even smaller (more negative) cSAR $\left(\mathrm{NO}_{2}\right)$ values (see rows 10 and 11 in Table 2). The participation of $\mathrm{NH}^{-}$in the H-bonding slightly reduces its donating properties; however, this can be compensated by weakening or total removal of the intermolecular interactions. Lengthening of the $\mathrm{N} \cdots \mathrm{F}$ distance allows negatively charged nitrogen atom to donate more electron density to the $\pi$-system, which results in stronger EAP of the $\mathrm{NO}_{2}$ group with $\operatorname{cSAR}\left(\mathrm{NO}_{2}\right)=$ -0.489 . And finally, in $p$-nitroanilide anion (row 12 in Table 2), where on the moiety in question no external perturbations exist, the negative charge at the nitrogen atom is able to fully participate in resonance interactions with the nitro group making its EAP the greatest, with $\operatorname{cSAR}\left(\mathrm{NO}_{2}\right)=-0.509$. All trends mentioned above are well illustrated by Fig. 6 (black diamonds). It can be seen that, depending on electronic properties of the reaction site $\mathrm{Y}$, EAP of the nitro group changes significantly, yielding $\mathrm{cSAR}\left(\mathrm{NO}_{2}\right)$ values in the range from -0.019 to -0.509 . Two monotonic trends are observed that correspond to different types of the studied systems (neutral and charged). 
Table 2 cSAR $\left(\mathrm{NO}_{2}\right)$ characteristics in simulated systems

\begin{tabular}{llllllll}
\hline$N$ & System & Interaction & $d(\mathrm{~N} \cdots \mathrm{F}) / \AA$ & $\varphi=0$ & $\varphi=30$ & $\varphi=60$ & $\varphi=90$ \\
\hline 1 & pNA cation $^{\mathrm{a}}$ & Free & - & -0.019 & -0.022 & -0.022 & -0.018 \\
2 & Nitrobenzene & Free & - & -0.146 & -0.149 & -0.143 & -0.131 \\
3 & $\mathbf{a}$ & $\mathrm{N} \cdots \mathrm{HF}$ & $\mathrm{Opt}^{\mathrm{b}}$ & -0.173 & -0.171 & -0.159 & -0.142 \\
4 & $\mathbf{a}$ & $\mathrm{N} \cdots \mathrm{HF}$ & 4.0 & -0.198 & -0.197 & -0.183 & -0.158 \\
5 & pNA & Free & - & -0.219 & -0.216 & -0.198 & -0.170 \\
6 & $\mathbf{b}$ & $\mathrm{NH} \cdots \mathrm{FH}$ & 4.0 & -0.235 & -0.223 & -0.205 & -0.183 \\
7 & $\mathbf{b}$ & $\mathrm{NH} \cdots \mathrm{FH}$ & $\mathrm{Opt}^{\mathrm{b}}$ & -0.239 & -0.228 & -0.210 & -0.187 \\
8 & $\mathbf{c}$ & $\mathrm{NH} \cdots \mathrm{F}^{-}$ & 2.8 & -0.311 & -0.302 & -0.277 & -0.231 \\
9 & $\mathbf{c}^{\mathrm{c}}$ & $\mathrm{NH} \cdots \mathrm{F}^{-}$ & $\mathrm{Opt}^{\mathrm{c}}$ & -0.399 & -0.395 & -0.373 & -0.280 \\
10 & $\mathbf{d}$ & $\mathrm{N}^{-} \cdots \mathrm{HF}$ & $\mathrm{Opt}^{\mathrm{b}}$ & -0.445 & -0.444 & -0.423 & -0.299 \\
11 & $\mathbf{d}$ & $\mathrm{N}^{-} \cdots \mathrm{HF}$ & 4.0 & -0.489 & -0.485 & -0.470 & -0.333 \\
12 & pNA anion $^{\mathrm{a}}$ & $\mathrm{Free}$ & - & -0.509 & -0.507 & -0.494 & -0.348 \\
\hline
\end{tabular}

Symbols of H-bonded systems correspond to the Scheme 2

${ }^{a} p$-Nitroanilinium cation and $p$-nitroanilide anion, respectively

${ }^{\mathrm{b}}$ Distance in equilibrium complex

${ }^{\mathrm{c}}$ Distance in complex without proton transfer, $d(\mathrm{~N} \cdots \mathrm{F})=2.65 \AA$

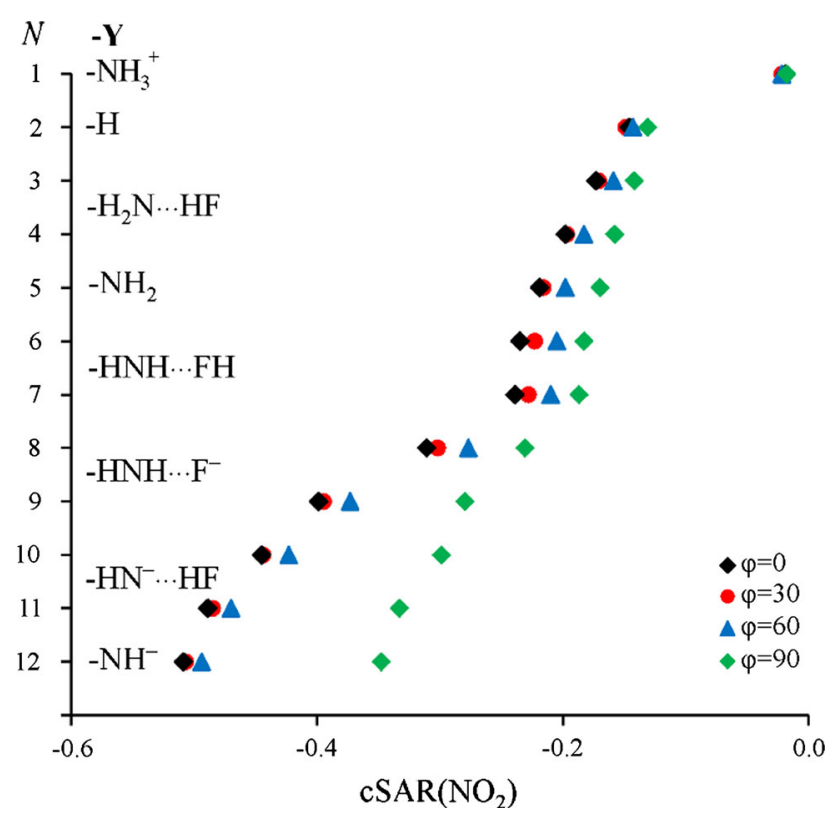

Fig. 6 Graphical illustration of $\mathrm{cSAR}\left(\mathrm{NO}_{2}\right)$ values, for $p$-nitrobenzene- $\mathrm{Y}$ derivatives (with $\mathrm{Y}=\mathrm{NH}^{-}, \mathrm{NH}_{2}, \mathrm{H}$ and $\mathrm{NH}_{3}{ }^{+}$), as a measure of reverse substituent effects. $N$ corresponds to the index number in Table 2

Additionally, to present that this approach can be generalized for estimation of the electronic properties of other substituents with varying EAP, the properties of the $\mathrm{NO}_{2}$ group were modified by rotation from coplanar to perpendicular orientation with respect to the benzene ring by angle $\varphi(0 \leq \varphi \leq 90)$ with step of $30^{\circ}$ (Table 2 ; Fig. 6). It can be observed that their responses to the change of the $\mathrm{Y}$ electronic properties show similar trends, but with different sensitivity. This means that the same reactive site $\mathrm{Y}$ influences the different substituents $\mathrm{X}$ to varying degrees. This is particularly visible for the cases 2-7 (neutral systems), where the trends are very similar. As expected, substituent $\mathrm{X}$ with $\varphi=0$ can withdraw more charge from the system than $\mathrm{X}$ with $\varphi=90$. The smallest effect of rotation is observed for the pNA cation $(\Delta \mathrm{cSAR}=0.004)$, and the greatest one is for the pNA anion $(\Delta \mathrm{cSAR}=0.161)$. Such substantial effect in the latter case can be explained by a significant lowering of the resonance effect between the $\mathrm{NH}^{-}$and perpendicular $\mathrm{NO}_{2}$ group.

\section{Conclusions}

Uniform approach to quantitative characteristics of both the reaction site $(\mathrm{Y})$ and substituent $(\mathrm{X})$ is presented. For this purpose, the charge of the substituent active region (cSAR) concept is used and applied for description of para-disubstituted benzene derivatives $\left(\mathrm{X}-\mathrm{C}_{6} \mathrm{H}_{4}-\mathrm{Y}\right)$. It has been shown that:

1. Different assessments of atomic charges (Voronoi, Hirshfeld, Mulliken, Bader and Weinhold) used for calculating the $\operatorname{cSAR}(\mathrm{X})$ and $\operatorname{cSAR}\left(\mathrm{NO}_{2}\right)$ values lead to a good qualitative agreement between them.

2. $\operatorname{cSAR}\left(\mathrm{NO}_{2}\right)$ parameter is a reliable descriptor of the EAP of the nitro group as the reaction site at the same level of reliability as the classical Hammett approach.

3. The EAP of the $\mathrm{NO}_{2}$ group as a substituent changes in a range 0.49 units of cSAR (Table 2). Applying a 
simple proportion, ${ }^{1}$ it is equivalent to the range of changes in the scale of the Hammett substituent constants $\sim 2.5$ units of $\sigma$. It is a measure how dramatically may change EAP of the group due to the moiety to which this is attached.

Therefore, application of the cSAR concept to quantitative measure of both classical and reverse substituent effects has been proposed. It should be stressed that the reverse substituent effect (showing the influence of reaction site $Y$ on the properties of substituent $\mathrm{X}$ ) is expressed in a quantitative and unified way. Moreover, the presented method is not sensitive to errors inherent in secondary substituent constants [2], which were usually obtained from different reference reactions [4] and hence might comprise not only experimental errors but also errors involved in fitting of these data to the primary standards, i.e., to $\sigma$ constants defined for meta-substituted benzoic acids. Application of the cSAR method makes the concept of substituent effects more understandable and might have a practical advantage for organic chemistry, in particular for targeted organic synthesis.

\section{Perspectives}

A good agreement between results in estimation of EAP/ EDP of substituents by application of the cSAR and Hammett-like approaches allow us to postulate a possibility of estimating EAP/EDP of a given group in any new molecular systems.

In particular, if a substituent, or more generally a functional group, is attached to a less known molecular moiety (i.e., with no possibility of application a typical Hammett-like approach), its electronic properties can be evaluated using linear regression between $\operatorname{cSAR}(X)$ values and Hammett constants for typical Hammett-like series: $\mathrm{X}-$ $\mathrm{Ph}-\mathrm{COOH}, \mathrm{NH}_{2}-\mathrm{Ph}-\mathrm{COOH}$ and $\mathrm{NO}_{2}-\mathrm{Ph}-\mathrm{COOH}$. Then, based on this regression, we may "translate" cSAR $(X)$ value calculated for a new system into the much more familiar numerical characteristic of the substituentthe Hammett constant. Certainly, other "normalization" procedures are also recommended in order to approach the cSAR values to other scales describing substituent effects.

Another fruitful field of research seems to be comparison of the cSAR characteristics of the substituent with quantum topological molecular descriptors of the substituents [44, 45] and of the transmitting moiety (ring) [46].

\footnotetext{
${ }^{1}$ In the case of the nitro group, the difference of its $\sigma$ constants for $p$ nitroaniline and $p$-nitrobenzoic acid is $1.27-0.78=0.49$, whereas the appropriate cSAR values are -0.219 and -0.119 , respectively (Table 1). The ratio of these differences is $\sim 5$. Thus, the ranges of cSAR values in Table 2 correspond to 2.5 units of $\sigma$.
}

Acknowledgments We gratefully acknowledge the Foundation for Polish Science for supporting this work under MPD/2010/4 project. H.S. and T.M.K. thank the National Science Centre and Ministry of Science and Higher Education of Poland for supporting this work under the Grant No. UMO-2013/11/B/ST4/00531.

Open Access This article is distributed under the terms of the Creative Commons Attribution 4.0 International License (http://creativecommons.org/licenses/by/4.0/), which permits unrestricted use, distribution, and reproduction in any medium, provided you give appropriate credit to the original author(s) and the source, provide a link to the Creative Commons license, and indicate if changes were made.

\section{References}

1. Hammett LP (1940) Physical organic chemistry. McGraw-Hill, New York, $p 184$

2. Jaffe HH (1953) Chem Rev 53:191-261

3. Exner O (1972) In: Chapman NB, Shorter J (eds) Advances in linear free energy relationships. Plenum Press, London, pp 1-70

4. Exner O (1978) In: Chapman NB, Shorter F (eds) Correlation analysis in organic chemistry-recent advances. Plenum Press, London, pp 439-541

5. Johnson CD (1973) The Hammett equation. Cambridge University Press, Cambridge

6. Shorter J (1991) In: Zalewski RI, Krygowski TM, Shorter J (eds) Similarity models in organic chemistry, biochemistry and related fields. Elsevier, Amsterdam, p 77

7. Hansch C, Leo A, Taft RW (1991) Chem Rev 91:165-195

8. Brown HC, Okamoto Y (1958) J Am Chem Soc 80:4979-4987

9. van Bekkum H, Verkade PE, Wepster BM (1959) Recl Trav Chim 78:815-850

10. Taft RW, Ehrenson S, Lewis IC, Glick RE (1959) J Am Chem Soc 81:5352-5361

11. Taft RW (1960) J Phys Chem 64:1805-1815

12. Norman ROC, Ralph PD (1963) J Chem Soc 5431-5436

13. Yukawa Y, Tsuno Y, Sawada M (1966) Bull Chem Soc Jpn 39:2274-2286

14. Exner O, Krygowski TM (1996) Chem Soc Rev 25:71-75

15. Irle S, Krygowski TM, Niu JE, Schwarz WHE (1996) J Org Chem 60:6744-6755

16. Kemula W, Krygowski TM (1979) In: Bard AJ, Lund H (eds) Encyclopedia of electrochemistry of the elements, vol XIII. Marcel Dekker Inc, New York, pp 77-130

17. Kuhn A, von Eschwege KG, Conradie J (2012) J Phys Org Chem 25:58-68

18. Sadlej-Sosnowska N (2007) Polish J Chem 81:1123-1134

19. Sadlej-Sosnowska N (2007) Chem Phys Lett 447:192-196

20. Krygowski TM, Sadlej-Sosnowska N (2011) Struct Chem $22: 17-22$

21. Kubinyi N (1993) QSAR in drug design. Theory, methods and applications. Escom, Leiden

22. Siodla T, Oziminski WP, Hoffmann M, Koroniak H, Krygowski TM (2014) J Org Chem 79:7321-7331

23. Krygowski TM, Oziminski WP (2014) J Mol Model 20:2352

24. te Velde G, Bickelhaupt FM, Baerends EJ, Fonseca Guerra C, van Gisbergen SJA, Snijders JG, Ziegler T (2001) J Comput Chem 22:931-967

25. Becke AD (1988) Phys Rev A At Mol Opt Phys 38:3098-3100

26. Lee C, Yang W, Parr RG (1988) Phys Rev B Condens Matter 37:785-789

27. Grimme S, Antony J, Ehrlich S, Krieg HA (2010) J Chem Phys 132:154104 
28. Becke AD, Johnson ER (2005) J Chem Phys 122:154104

29. Snijders JG, Baerends EJ, Vernooijs P (1981) At Data Nucl Data Tables 26:483-509

30. Bickelhaupt FM, van Eikema Hommes NJR, Fonseca Guerra C, Baerends EJ (1996) Organometallics 15:2923-2931

31. Fonseca Guerra C, Handgraaf J-W, Baerends EJ, Bickelhaupt FM (2004) J Comput Chem 25:189-210

32. Hirshfeld FL (1977) Theor Chim Acta 44:129-138

33. Mulliken RS (1955) J Chem Phys 23:1833-1840

34. Mulliken RS (1955) J Chem Phys 23:1841-1846

35. Mulliken RS (1955) J Chem Phys 23:2338-2342

36. Mulliken RS (1955) J Chem Phys 23:2343-2346

37. Bader RWF (1990) Atoms in molecules: a quantum theory. Clarendon Press, Oxford

38. Weinhold F, Landis CR (2005) Valency and bonding. A natural bond orbital donor-acceptor perspective. Cambridge University Press, Cambridge

39. Frisch MJ, Trucks GW, Schlegel HB, Scuseria GE, Robb MA, Cheeseman JR, Scalmani G, Barone V, Mennucci B, Petersson GA, Nakatsuji H, Caricato M, Li X, Hratchian HP, Izmaylov AF, Bloino J, Zheng G, Sonnenberg JL, Hada M, Ehara M, Toyota K, Fukuda R, Hasegawa J, Ishida M, Nakajima T, Honda Y, Kitao O, Nakai H, Vreven T, Montgomery Jr JA, Peralta JE, Ogliaro F,
Bearpark M, Heyd JJ, Brothers E, Kudin KN, Staroverov VN, Kobayashi R, Normand J, Raghavachari K, Rendell A, Burant JC, Iyengar SS, Tomasi J, Cossi M, Rega N, Millam MJ, Klene M, Knox JE, Cross JB, Bakken V, Adamo C, Jaramillo J, Gomperts R, Stratmann RE, Yazyev O, Austin AJ, Cammi R, Pomelli C, Ochterski JW, Martin RL, Morokuma K, Zakrzewski VG, Voth GA, Salvador P, Dannenberg JJ, Dapprich S, Daniels AD, Farkas Ö, Foresman JB, Ortiz JV, Cioslowski J, Fox DJ (2009) GAUSSIAN 09 (Revision B.01) Gaussian Inc, Wallingford CT

40. Keith TA (2012) AIMAll (Version 12.06.03), TK Gristmill Software, Overland Park, KS (aim.tkgristmill.com)

41. Glendening ED, Badenhoop JK, Reed AE, Carpenter JE, Bohmann JA, Morales CM, Weinhold, F (2004) NBO 5.0G. Theoretical Chemistry Institute, University of Wisconsin, Madison, WI. http://www.chem.wisc.edu/ nbo5

42. Wiberg KB, Rablen PR (1993) J Comput Chem 14:1504-1518

43. Gross KC, Seybold PG, Hadad CM (2002) Int J Quantum Chem 90:445-458

44. Popelier PLA (1999) J Phys Chem A 103:2883-2890

45. Chaudry UA, Popelier PLA (2004) J Org Chem 69:233-241

46. Griffiths MZ, Popelier PLA (2013) J Chem Inf Model 53:17141725 